\title{
Performance and Internal Flow of a Dental Air Turbine Handpiece
}

\author{
Yasuyuki Nishi $\mathbb{D}^{1},{ }^{1}$ Hikaru Fushimi, ${ }^{2}$ Kazuo Shimomura, ${ }^{3}$ and Takeshi Hasegawa ${ }^{4}$ \\ ${ }^{1}$ Department of Mechanical Engineering, Ibaraki University, 4-12-1 Nakanarusawa-cho, Hitachi-shi, Ibaraki 316-8511, Japan \\ ${ }^{2}$ Graduate School of Science and Engineering, Ibaraki University, 4-12-1 Nakanarusawa-cho, Hitachi-shi, Ibaraki 316-8511, Japan \\ ${ }^{3}$ Yoshida Seiko, Ltd., 660 Yakimaki, Namegata-shi, Ibaraki 311-3506, Japan \\ ${ }^{4}$ The Yoshida Dental MFG Co., Ltd., 1-3-6 Kotobashi, Sumida-ku, Tokyo 130-8516, Japan
}

Correspondence should be addressed to Yasuyuki Nishi; yasuyuki.nishi.fe@vc.ibaraki.ac.jp

Received 30 October 2017; Accepted 28 December 2017; Published 30 January 2018

Academic Editor: Ryoichi Samuel Amano

Copyright (c) 2018 Yasuyuki Nishi et al. This is an open access article distributed under the Creative Commons Attribution License, which permits unrestricted use, distribution, and reproduction in any medium, provided the original work is properly cited.

\begin{abstract}
An air turbine handpiece is a dental abrasive device that rotates at high speed and uses compressed air as the driving force. It is characterized by its small size, light weight, and painless abrading due to its high-speed rotation, but its torque is small and noise level is high. Thus, to improve the performance of the air turbine handpiece, we conducted a performance test of an actual handpiece and a numerical analysis that modeled the whole handpiece; we also analyzed the internal flow of the handpiece. Results show that experimental and calculated values were consistent for a constant speed load method with the descending speed of $1 \mathrm{~mm} / \mathrm{min}$ for torque and turbine output. When the tip of the blade was at the center of the nozzle, the torque was at its highest. This is likely because the jet from the nozzle entered the tip of the blade from a close distance that would not reduce the speed and exited along the blade.
\end{abstract}

\section{Introduction}

An air turbine handpiece is highly valued as a dental abrasive device that rotates at a high speed, and it is an essential device for dental treatment [1]. Since its development, many studies have been conducted to measure and evaluate rotation performance [2-6] and measure and evaluate noise [7, 8]. An air turbine handpiece uses compressed air as the driving force and is characterized by its small size, light weight, and painless abrading at high rotation speed. However, compared to an electric handpiece that uses a motor as the driving force, its torque is small and noise level is high.

As such, improved performance and reduced noise for an air turbine handpiece are desired. Considering that an air turbine handpiece has the equivalent rotation performance as turbine performance, it can be considered as a type of turbomachinery, and the fluid mechanics approach would be effective. In other words, it would be effective to first elucidate the internal flow of an air turbine handpiece and the relation between the performance and the noise characteristics and then control the flow. However, the main component of an air turbine handpiece, the rotor, is small and rotates at high speeds $\left(250,000-400,000 \mathrm{~min}^{-1}\right)$; thus, measuring the flow is not easy. In addition, the torque generated by the rotor is extremely small; thus, the measurement of torque is difficult. With the progress of computational fluid dynamics analysis, numerical analysis of internal flow to the head (turbine) of handpiece began recently [9-13], and numerical analysis that models the entire handpiece [14] has also been conducted. However, in these studies, details of internal flow are insufficiently elucidated, and there is no verification of numerical analysis results via experiment. As such, there are few reports on the study of internal flow in an air turbine handpiece.

In this study, as the first step toward improving the performance of air turbine handpiece, we conducted a performance test of an actual handpiece while conducting numerical analysis that models the whole handpiece, and we compared the turbine performances. Furthermore, we examined the torque fluctuation with the rotation of the rotor and examined its relation with the internal flow. 


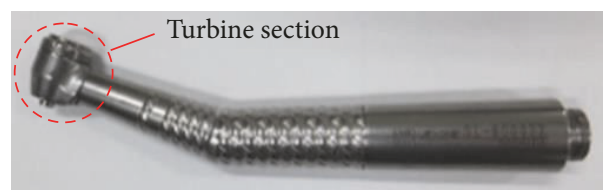

FIgURE 1: Air turbine handpiece.

TABLE 1: Specifications of turbine section.

\begin{tabular}{lcc}
\hline Nozzle & $d:$ nozzle inner diameter $[\mathrm{mm}]$ & 1.3 \\
& Number of nozzles & 1 \\
\hline \multirow{3}{*}{ Rotor } & $D_{1}:$ rotor outer diameter $[\mathrm{mm}]$ & 8.8 \\
& $D_{2}:$ rotor inner diameter $[\mathrm{mm}]$ & 3.6 \\
& $b$ : blade width $[\mathrm{mm}]$ & 3.3 \\
& $\beta:$ blade angle $\left[{ }^{\circ}\right]$ & 90 \\
Casing & Number of blades & 8 \\
\hline
\end{tabular}

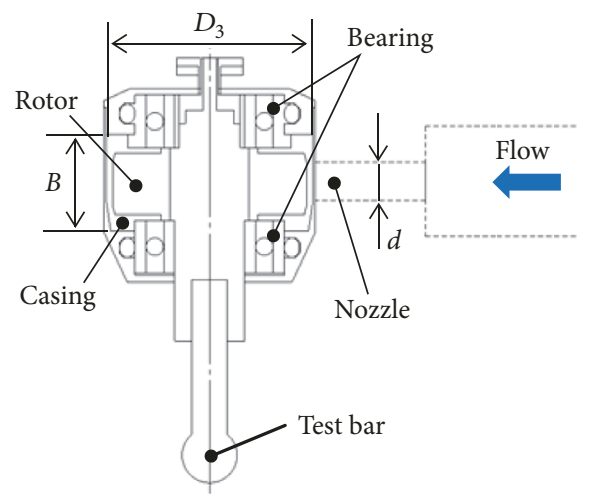

Figure 2: Schematic of turbine section.

\section{Experimental Apparatus and Methods}

2.1. Test Air Turbine Handpiece. Figure 1 shows the test air turbine handpiece and Table 1 shows its specifications. In addition, Figure 2 shows the schematic of the turbine section. The turbine section, which forms the head section of the handpiece, comprises a nozzle, rotor, and casing and is a single-stage impulse turbine. Figure 3 shows the rotor, while Figure 4 shows its schematic. This air turbine handpiece jets out the compressed air that enters from the entrance through the nozzle, and the air is driven as the jet works on the rotor. The inner diameter of the nozzle is $d=1.3 \mathrm{~mm}$, and there is one nozzle. The outer diameter of the rotor is $D_{1}=8.8 \mathrm{~mm}$, while the inner diameter is $D_{2}=3.6 \mathrm{~mm}$ and the blade width is $b=3.3 \mathrm{~mm}$, of which there are eight blades.

2.2. Experimental Apparatus and Methods. The rotation performance of the air turbine handpiece is assumed to be equivalent to turbine performance, and there are two methods to measure this value. One is when a test bar is loaded onto a work material at a constant speed, and the

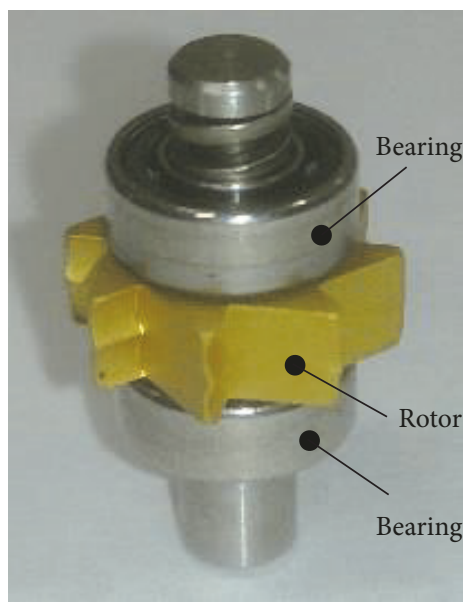

Figure 3: Rotor.

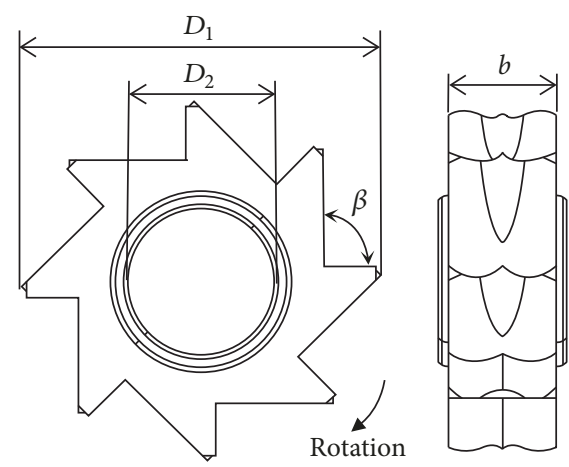

FIGURE 4: Schematic of rotor.

other is when the test bar is loaded onto a work material at a constant load [2]. Experimental results from the constant speed load method with the descending speed of $1 \mathrm{~mm} / \mathrm{min}$ are consistent with the constant load method [2]. Thus, in this study, we used the constant speed load method, which has a relatively easy mechanism and makes experiments simpler. The experimental apparatus is shown in Figure 5, and its schematic is shown in Figure 6. An air turbine handpiece with a test bar (cemented carbide with radius $r=1 \mathrm{~mm}$ ) attached to the rotational axis of the rotor is fixed in the movable part and is lowered at a constant speed. Compressed air of $0.22 \mathrm{MPa}$ is injected through the inlet of the handpiece, and when the rotor is turned on, the test bar is rotated. At this time, the pressure was adjusted according to the regulator (SMC Corporation; AW2000) installed at the handpiece inlet, and measured using a pressure gauge (Asahi Gauge Manufacturing Co., Ltd.; 101-F510, accuracy $\pm 1.6 \%$ of full scale). The 


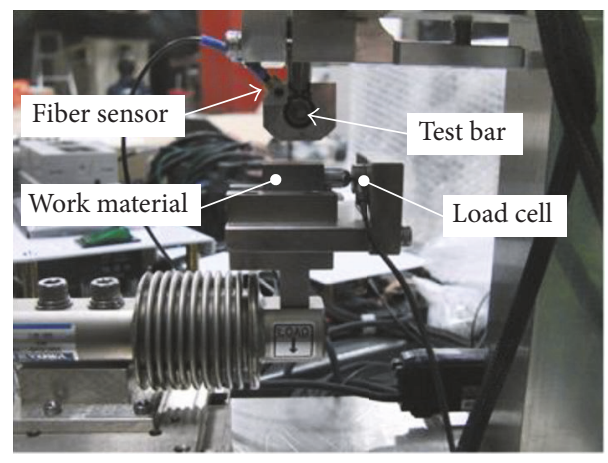

FIGURE 5: Experimental apparatus.

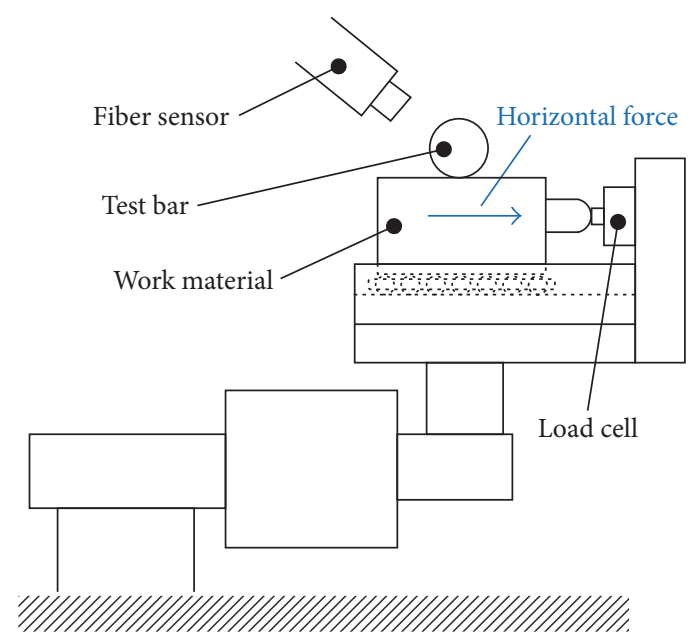

Figure 6: Schematic of experimental apparatus.

test bar is lowered at a descending speed of $1 \mathrm{~mm} / \mathrm{min}$, and the freely rotating test bar is pressed against the work material (cemented carbide) on the support stage. The horizontal force at this time $F_{H}$ and rotational speed $n$ were continuously measured with the load cell (Kyowa Electronic Instruments Co., Ltd.; LMB-A-100N, nonlinearity $\pm 0.5 \%$ rated output) and fiber sensor (KEYENCE CORPORATION; FU-20/FS-N11N). The torque $T$ and turbine output $L$ were then obtained with the following equations using the horizontal force $F_{H}$ and rotational speed $n$ that were measured:

$$
\begin{aligned}
& T=\frac{F_{H} r}{1000}, \\
& L=\frac{2 \pi n T}{60} .
\end{aligned}
$$

\section{Numerical Analysis Method and Conditions}

In this study, we performed a $3 \mathrm{D}$ compressible unsteady flow analysis by modeling the whole air turbine handpiece. For the analysis, we used general-purpose thermal fluid analysis software, ANSYS CFX14.5 (ANSYS, Inc.), and the working fluid was air. The governing equations were the mass conservation equation, momentum conservation equation, energy conservation equation, and ideal gas law [15], which were solved with the finite volume method. Furthermore, we used the Shear Stress Transport (SST) model [16] as the turbulence model.

Figure 7 shows the computational model for the whole air turbine handpiece, and Figure 8 shows the turbine section region. The calculation regions are inlet flow region, turbine section region, and outlet flow region. The numbers of computational elements were approximately 391,000, 1,127,000, and 783,000 for the inlet flow region, the turbine section region, and the outlet flow region, respectively, corresponding to a total number of elements of approximately 2,301,000. Boundary conditions were a total pressure of $0.22 \mathrm{MPa}$ and static temperature of $25^{\circ} \mathrm{C}$ for the inlet boundary and static pressure of $0 \mathrm{~Pa}$ for the outlet boundary. In addition, we provided arbitrary rotation speed to the rotor region, and the wall surface had adiabatic and nonslip conditions. The boundary between the rotational region and static region was attached using the Transient Rotor-Stator [17]. Time step size was determined the rotor rotates once with 120 steps at any speed. Calculations were continued until fluctuations in the torque stabilized. In terms of grid dependency, the number of computational elements was increased approximately 1.52 times, and it was analyzed with a rotation rate of $n=$ $250,000 \mathrm{~min}^{-1}$. The result was that this decreased by approximately $2.2 \%$ in relation to the torque in this paper, and it was confirmed that the effect of the number of computational elements was comparatively small.

For the coordinate system, we defined $x$-and $y$-axes as in Figure 5. For the blade phase angle $\theta^{*}$, the position at which the front surface of the reference Blade A is parallel to the $y$-axis (the position in Figure 5) is set as $\theta^{*}=$ $0^{\circ}$, and the counterclockwise direction was set as positive. Furthermore, we defined the blade ahead of Blade A as Blade $B$. The cross-section at $3.7 \mathrm{~mm}$ from the rotation center in the perpendicular direction to the front surface of Blades $A$ and $\mathrm{B}$ was defined as cross-section $\mathrm{a}-\mathrm{a}$, and the cross-section at $4.1 \mathrm{~mm}$ was defined as cross-section $\mathrm{b}-\mathrm{b}$.

\section{Results and Discussion}

4.1. Turbine Performance. Figure 9 shows the relation between torque $T$ and rotational speed $n$, while Figure 10 shows the relation between turbine output $L$ and rotational speed $n$. Figures 9 and 10 show that calculated $T$ and $L$ are slightly higher than the experimental values, but both $T$ and $L$ are consistent. Considering that calculated $T$ and $L$ ignore the loss of mechanical friction on the bearing, these analytical results are valid. Experimental and calculated $T$ decreased with increase in rotational speed, and calculated $L$ showed the maximum value at $n=250,000 \mathrm{~min}^{-1}(L=12.1 \mathrm{~W})$.

Next, to search the locations where loss inside of the handpiece is high, we created a measurement surface in seven locations, as shown in Figure 11, and obtained entropy $E$ for each measurement surface. Figure 12 shows the entropy $E$ on each measurement surface for the handpiece when the maximum output rotational speed was $n=250,000 \mathrm{~min}^{-1}$. Figure 12 shows that $E$ demonstrated the highest increase in locations that are equivalent to the rotor region inside of F4-F5 


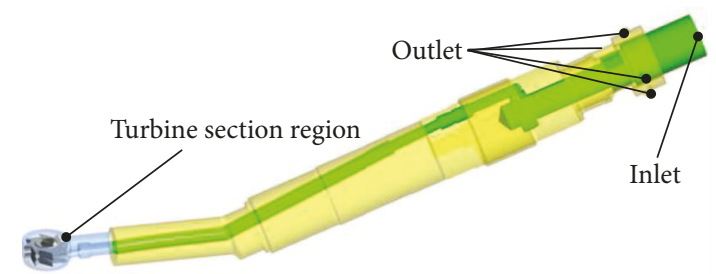

FIGURE 7: Air turbine handpiece model.
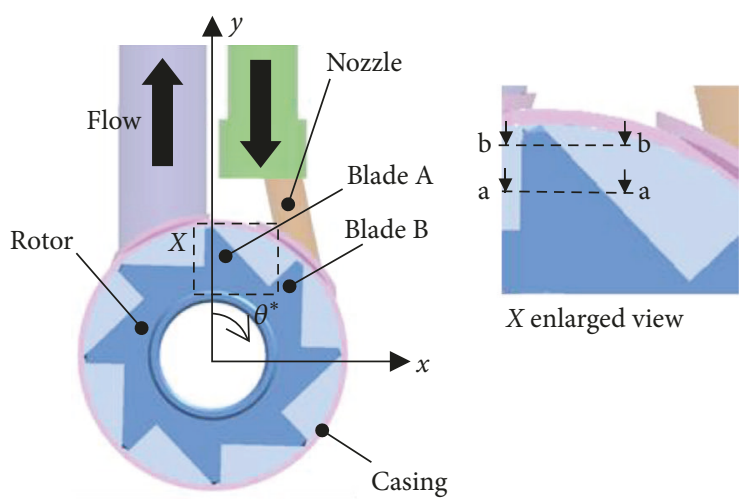

$X$ enlarged view

FIGURE 8: Turbine section region.

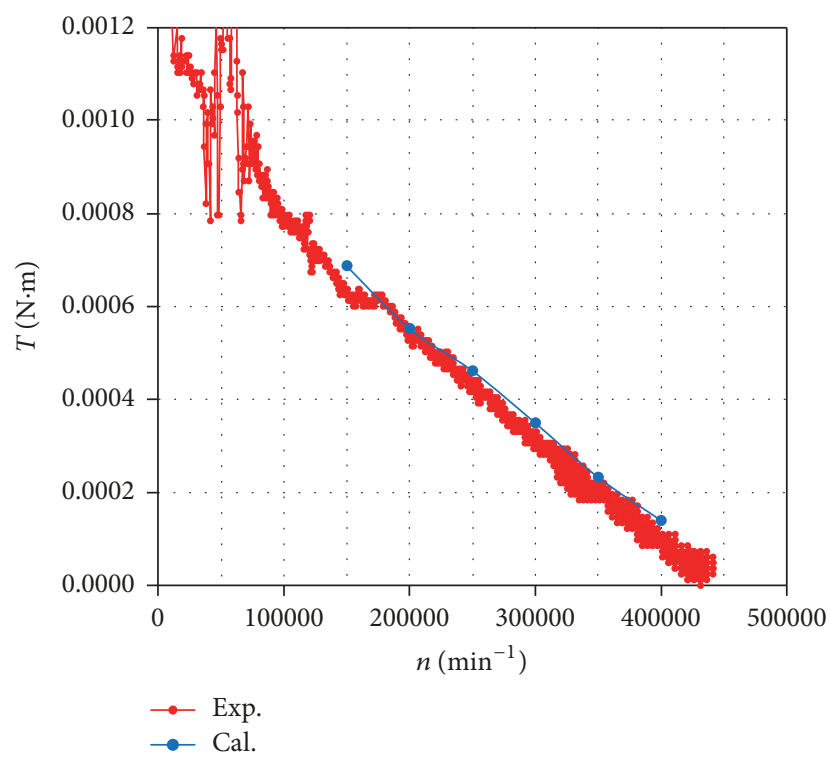

FIGURE 9: Correlation between rotational speed and torque.

casing among measurement surfaces. Therefore, in terms of the loss inside of the handpiece, the loss in the rotor region is the most dominant. However, $E$ increased slightly in F1-F4 inlet flow and F6-F7 outlet flow; thus, the loss in the inlet and outlet flows cannot be ignored.

We obtained adiabatic efficiency $\eta_{\text {ad }}$ of the turbine section and the whole handpiece with the following equations:

$$
\eta_{\mathrm{ad}}=\frac{L}{L_{\mathrm{ad}}}
$$

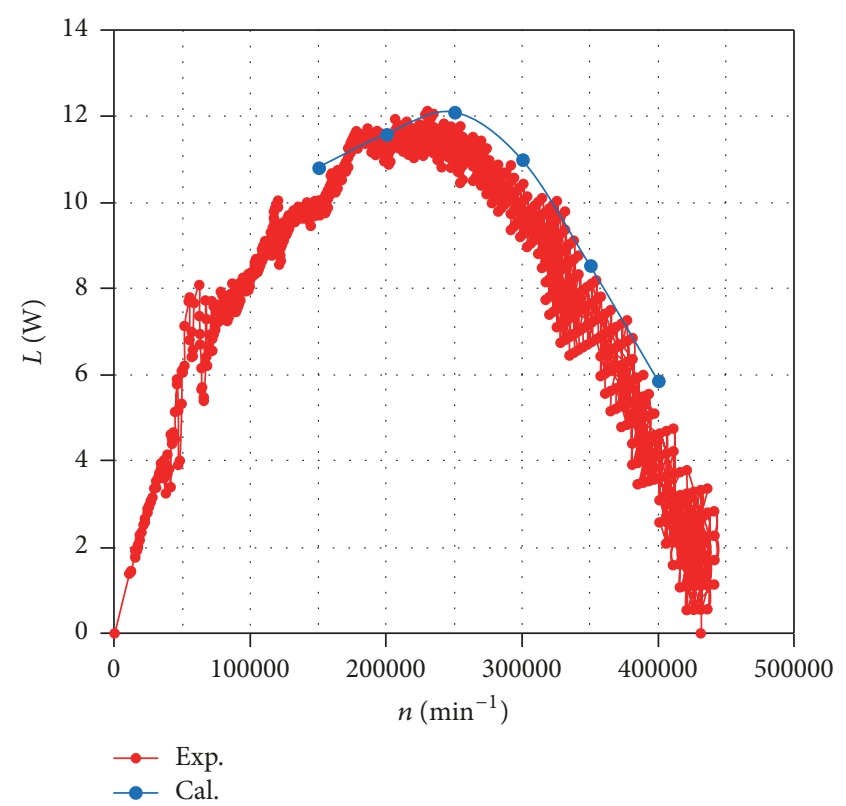

FIGURE 10: Correlation between rotational speed and turbine output.

$$
\begin{aligned}
& L_{\mathrm{ad}} \\
& \quad=\dot{m}\left[\frac{\kappa}{\kappa-1} \frac{P_{1}}{\rho_{1}}\left\{1-\left(\frac{P_{2}}{P_{1}}\right)^{(\kappa-1) / \kappa}\right\}+\frac{1}{2}\left(v_{1}^{2}-v_{2}^{2}\right)\right],
\end{aligned}
$$

where $\dot{m}$ is the mass flow rate and $\kappa$ is the specific heat ratio (1.4). $\rho_{1}, P_{1}$, and $v_{1}$ are fluid density, static pressure, and 

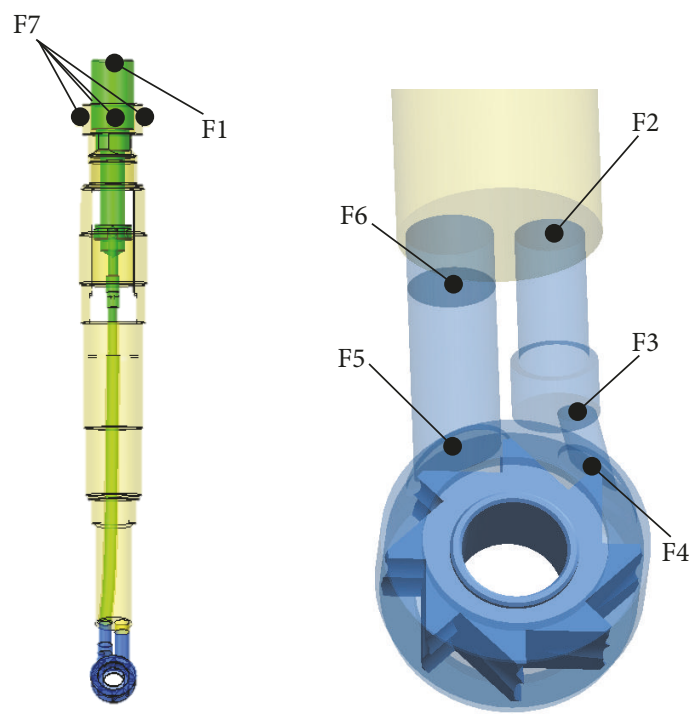

FIGURE 11: Measuring surface.

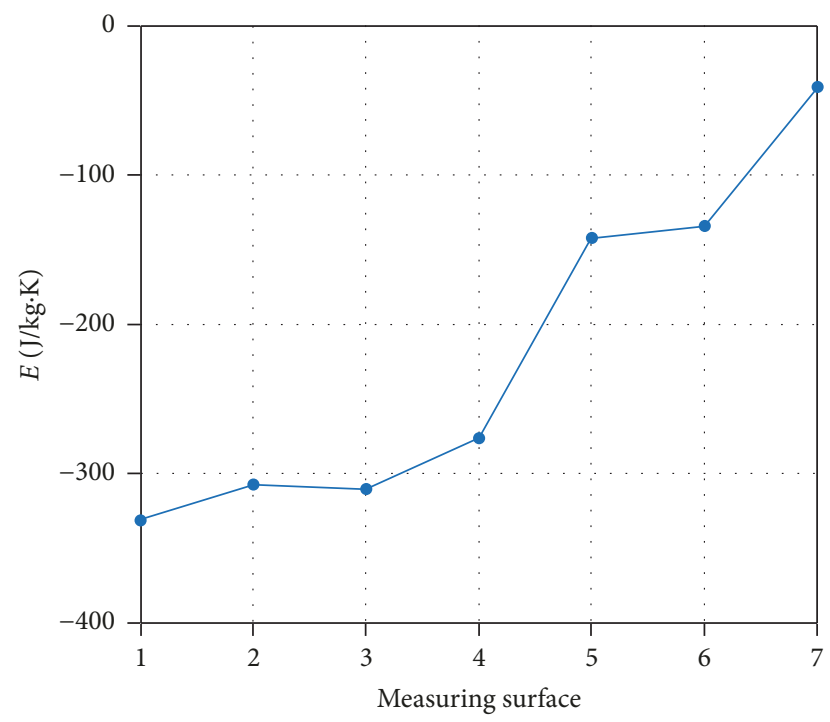

FIGURE 12: Entropy at each measuring surface.

absolute velocity at the inlet, respectively. To calculate $\eta_{\mathrm{ad}}$ of the turbine section, we used the value from the turbine section inlet (F2); to calculate $\eta_{\mathrm{ad}}$ of the whole handpiece, we used the value from the handpiece inlet (F1). $P_{2}$ and $v_{2}$ are static pressure and absolute velocity at the outlet, respectively, and to calculate $\eta_{\mathrm{ad}}$ of the turbine section we used the value from the turbine section outlet (F6), and to calculate $\eta_{\text {ad }}$ of the whole handpiece, we used the value from the handpiece outlet (F7).

Figure 13 shows the relation between adiabatic efficiency $\eta_{\text {ad }}$ and rotational speed $n$ of the turbine section and the whole handpiece. Figure 13 shows that $\eta_{\mathrm{ad}}$ of the turbine section and the whole handpiece present the maximum value when $n=$ $250,000 \mathrm{~min}^{-1}$, which is similar to the maximum value of the turbine output, and they show a major drop at high rotational

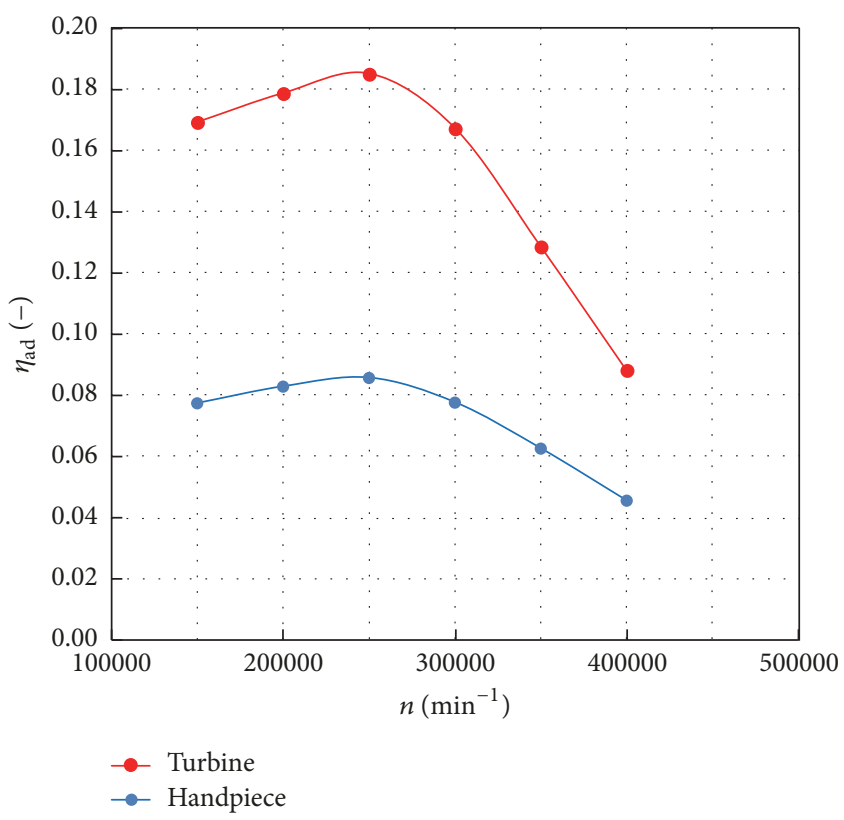

FIGURE 13: Correlation between rotational speed and adiabatic efficiency.

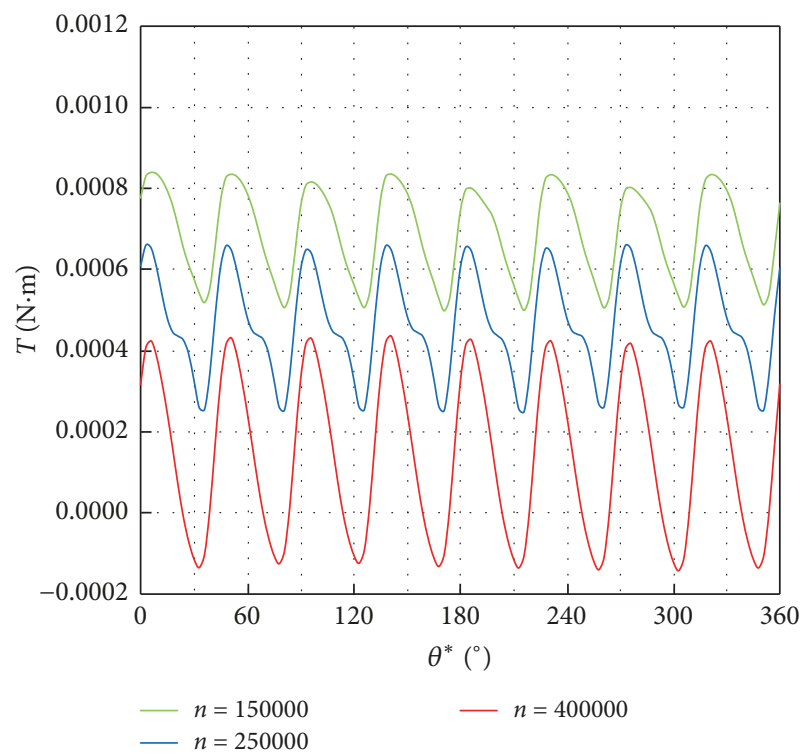

FIGURE 14: Torque fluctuation during one rotation of rotor.

speed. The maximum $\eta_{\mathrm{ad}}$ of the turbine section was quite low at 0.185 . The maximum $\eta_{\mathrm{ad}}$ of the whole handpiece was 0.086 , and this is approximately $46 \%$ less than the maximum $\eta_{\text {ad }}$ of the turbine section.

4.2. Torque Fluctuation and Internal Flow. Figure 14 shows the torque fluctuation during one rotor rotation for each rotational speed $n$. Figure 14 shows that $T$ fluctuates greatly during one rotor rotation, showing eight peaks in response to the number of blades. Fluctuation in $T$ increases with increased rotational speed, and especially at $n=400,000 \mathrm{~min}^{-1}$, the 


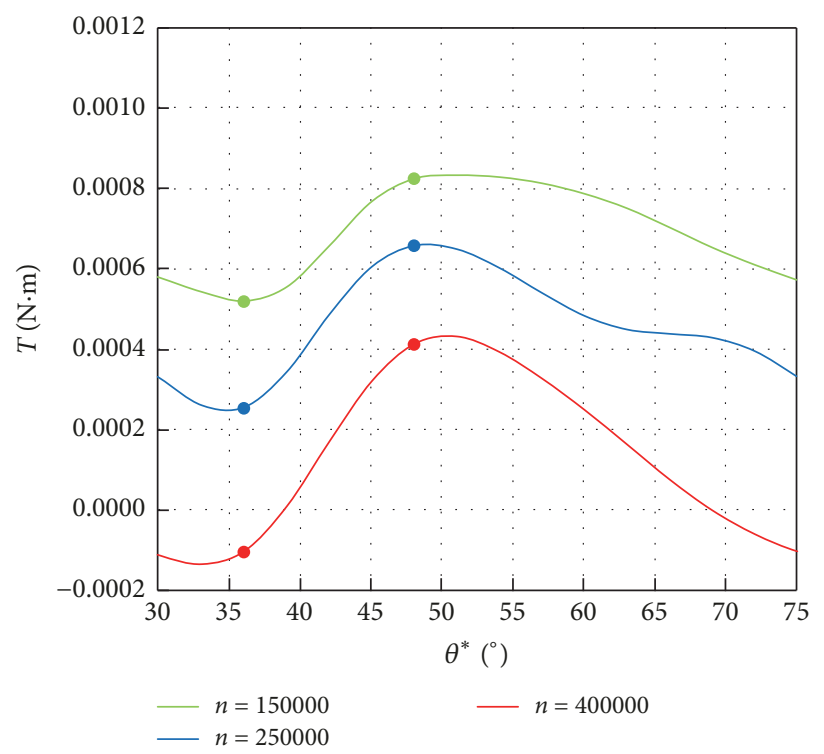

Figure 15: Torque fluctuation for one blade pitch.

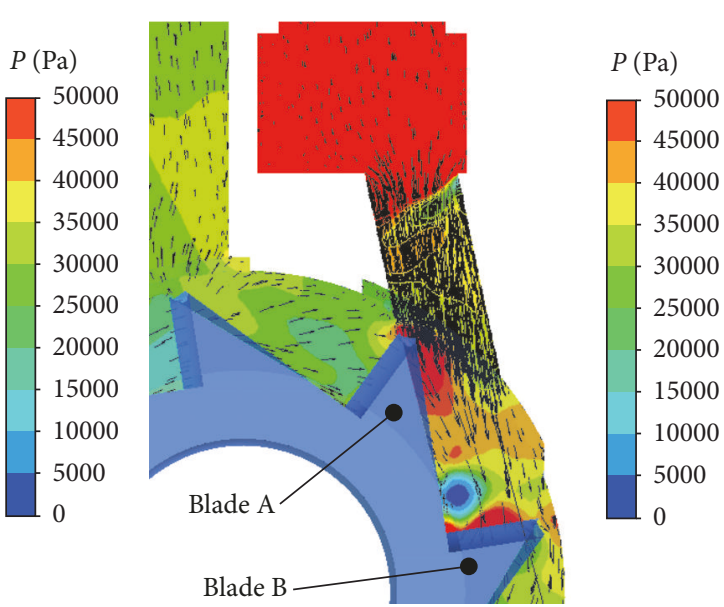

(a) $\theta^{*}=36^{\circ}$

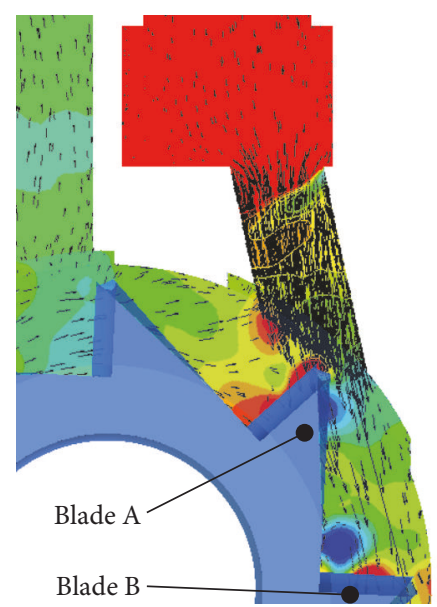

(b) $\theta^{*}=48^{\circ}$

FIGURE 16: Static pressure distributions and absolute velocity vectors $\left(n=250,000 \mathrm{~min}^{-1}\right)$.

minimum value presents a negative value. When torque fluctuation increases, it lowers workability of the air turbine headpiece and causes fluid noise; thus, suppression of these issues is a challenge. Since torque fluctuates, periodically to the number of blades, torque fluctuation for one blade pitch is shown in Figure 15. Figure 15 shows that when the blade phase angle is around $\theta^{*}=36^{\circ}, T$ becomes a minimum. Subsequently, $T$ increases rapidly and after reaching the maximum around $\theta^{*}=48^{\circ}$, it gradually decreases.

Therefore, we focused on these blade phase angles and examined the internal flow. First, we present static pressure distribution and absolute velocity vectors for the center crosssection of the blade width for each blade phase angle $\left(\theta^{*}=\right.$ $\left.36^{\circ}, 48^{\circ}\right)$ at the maximum output rotational speed of $n=$ 250,000 $\mathrm{min}^{-1}$ (Figures 16(a) and 16(b)). Figures 17-24 show static pressure distribution and absolute velocity vectors of cross-sections $\mathrm{a}-\mathrm{a}$ and $\mathrm{b}-\mathrm{b}$ for each blade (Blade A and Blade B).

At $\theta^{*}=36^{\circ}$, where $T$ becomes minimum, Figure 16(a) shows that with Blade A the jet from the nozzle does not enter the front surface of the blade, but it collides with the back surface of the blade. Therefore, as shown in Figures 17(a) and 17(b), static pressure increases on the back surface of the blade. Especially on the cross-section $\mathrm{b}-\mathrm{b}$ with a large radius, static pressure increased more than the static pressure on the cross-section a-a. Thus, there was a large negative torque on the Blade A. With Blade B, jet flows facing the front surface of the blade. The larger shift in the flow from entering to exiting the blade causes the torque to also increase more. However, since the distance between the nozzle and blades is large, the jet decreases its speed and spreads in the width direction of the blade. Therefore, as shown in Figures 18(a) 


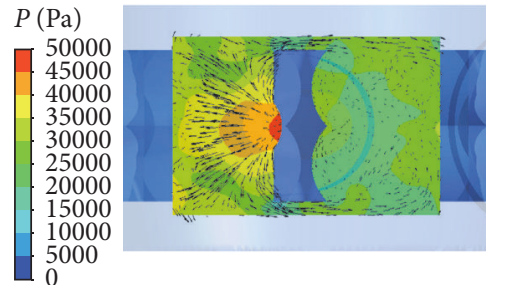

(a) Section a-a

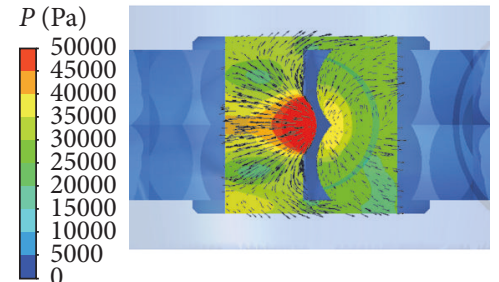

(b) Section b-b

FIGURE 17: Static pressure distributions and absolute velocity vectors of Blade A $\left(\theta^{*}=36^{\circ}, n=250,000 \mathrm{~min}^{-1}\right)$.

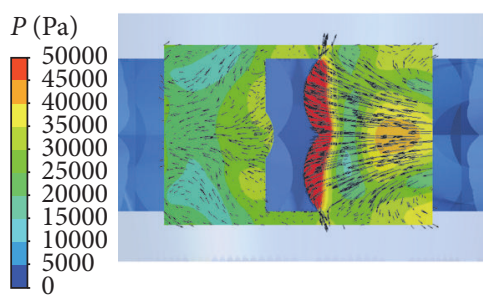

(a) Section a-a

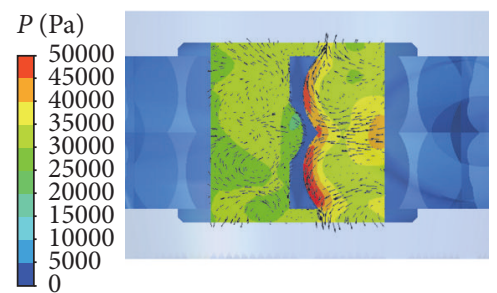

(b) Section b-b

FIGURE 18: Static pressure distributions and absolute velocity vectors of Blade B $\left(\theta^{*}=36^{\circ}, n=250,000 \mathrm{~min}^{-1}\right)$.

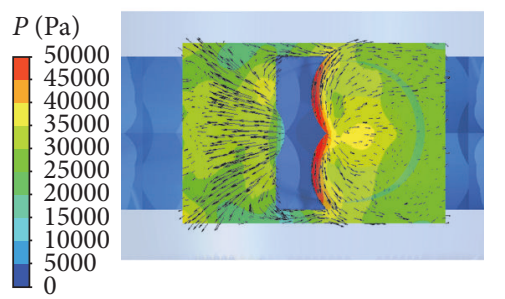

(a) Section a-a

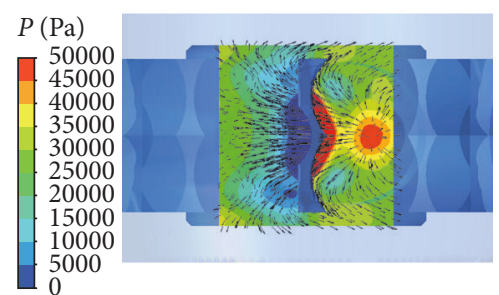

(b) Section b-b

FIGURE 19: Static pressure distributions and absolute velocity vectors of Blade $\mathrm{A}\left(\theta^{*}=48^{\circ}, n=250,000 \mathrm{~min}^{-1}\right)$.

and 18(b), the flow does not exit along the blade in both crosssections, and the shift in the flow is small. Therefore, although static pressure on the front surface of the blade on the crosssection a-a increases considerably, static pressure on the back surface of the blade is also large; moreover, as it is near the center of the blade with a small radius, it does not sufficiently contribute to the torque. Based on the above, torque near $\theta^{*}$ $=36^{\circ}$ presented the minimum value.

In contrast, at $\theta^{*}=48^{\circ}$ where $T$ becomes maximum, as shown in Figure 16(b), the blade tip of Blade $A$ is positioned near the center of the nozzle, and the jet from the nozzle flows to the tip of the Blade $\mathrm{A}$ at a close distance where the jet does not lose its speed. Therefore, as shown in Figure 19(b), the flow that entered the front surface of the blade on crosssection $\mathrm{b}-\mathrm{b}$ flowed out along the blade and static pressure at the front surface of the blade increased, while static pressure on the back surface of the blade decreased. The pressure difference between the front and back surfaces of this blade tip with a large radius is greatly contributing to the torque. As shown in Figure 19(a), since cross-section a-a represents the moment just before Blade A reaches the nozzle, static pressure increase on the front surface of the blade was slightly lower. With Blade B, the distance between the nozzle and blade is larger, and the jet is prevented by Blade A. Therefore, as shown in Figures 20(a) and 20(b), based on the static pressure distribution on the front and back surfaces of the blade, torque on Blade $\mathrm{B}$ is smaller than when $\theta^{*}=36^{\circ}$. As such, near $\theta^{*}=48^{\circ}$, torque at the tip of Blade A becomes dominant, leading to maximum torque.

Furthermore, we examined the internal flow at low and high rotational speed. Figures 21(a), 21(b), 22(a), and 22(b) show static pressure distribution and the absolute velocity vector of central cross-section of the blade width for each blade phase angle $\left(\theta^{*}=36^{\circ}, 48^{\circ}\right)$ at $n=150,000 \mathrm{~min}^{-1}$ and $n=400,000 \mathrm{~min}^{-1}$. Figures 23-26 and Figures 27-30 show static pressure distribution and absolute velocity vector of cross-sections $\mathrm{a}-\mathrm{a}$ and $\mathrm{b}-\mathrm{b}$ for Blades $\mathrm{A}$ and $\mathrm{B}$, respectively.

Figures 21(a) and 21(b) show that, at $n=150,000 \mathrm{~min}^{-1}$, static pressure on the front surface of Blade $B$ at $\theta^{*}=36^{\circ}$ and $\theta^{*}=48^{\circ}$ increased more than at $n=250,000 \mathrm{~min}^{-1}$. This is because decreased rotational speed increased the relative speed of the jet to the blade. Thus, as shown in Figures 23-26, compared to when $n=250,000 \mathrm{~min}^{-1}$, the jet does not spread 


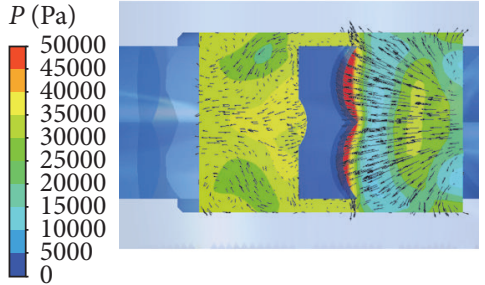

(a) Section a-a

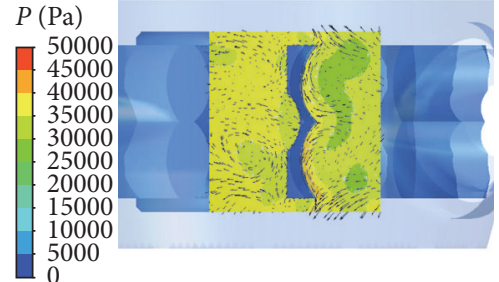

(b) Section b-b

FIgURE 20: Static pressure distributions and absolute velocity vectors of Blade B $\left(\theta^{*}=48^{\circ}, n=250,000 \mathrm{~min}^{-1}\right)$.

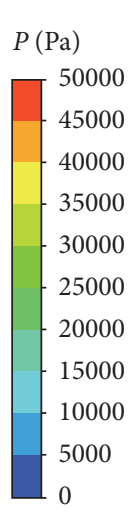

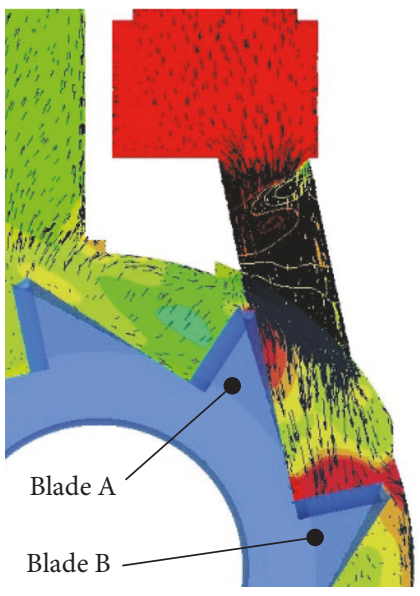

(a) $\theta^{*}=36^{\circ}$

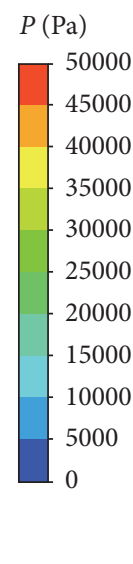

(b) $\theta^{*}=48^{\circ}$

FIGURE 21: Static pressure distributions and absolute velocity vectors $\left(n=150,000 \mathrm{~min}^{-1}\right)$.

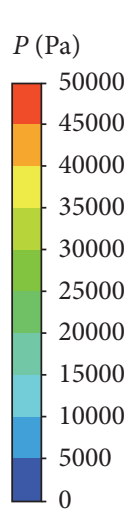

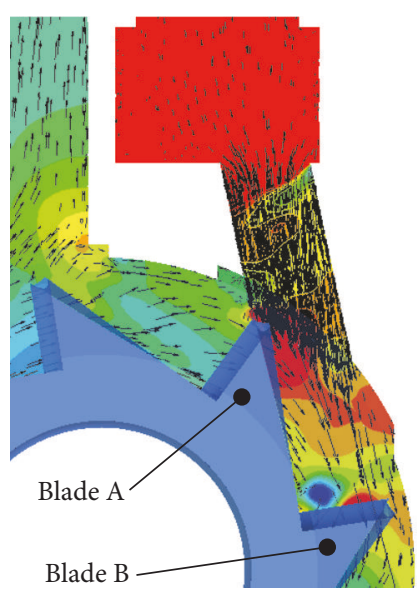

(a) $\theta^{*}=36^{\circ}$
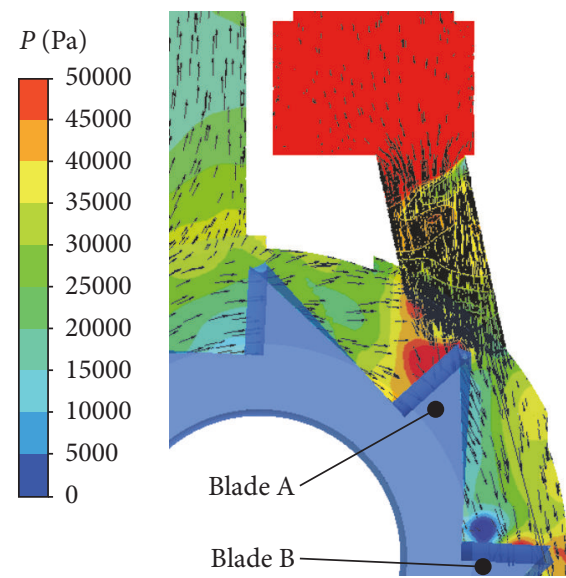

(b) $\theta^{*}=48^{\circ}$

FIGURE 22: Static pressure distributions and absolute velocity vectors $\left(n=400,000 \mathrm{~min}^{-1}\right)$.

to the blade width direction, and flow that entered the front surface of the blade flows out along the blade. Therefore, the shift in the flow increases, and as shown in Figure 14, at $n=150,000 \mathrm{~min}^{-1}$, torque increased.
On the contrary, Figures 22(a) and 22(b) show that, at $n=400,000 \mathrm{~min}^{-1}$, static pressure on the front surface of Blade $\mathrm{B}$ at $\theta^{*}=36^{\circ}$ and $\theta^{*}=48^{\circ}$ decreased compared to when $n=250,000 \mathrm{~min}^{-1}$. As rotational speed increased, the 


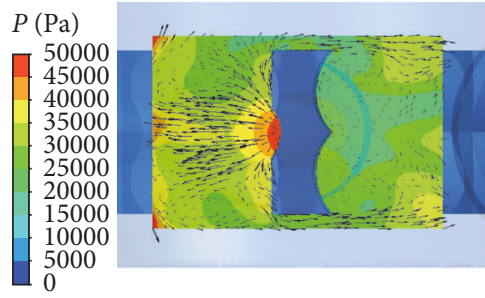

(a) Section a-a

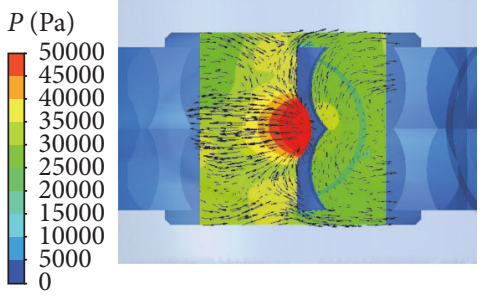

(b) Section b-b

FIGURE 23: Static pressure distributions and absolute velocity vectors of Blade $\mathrm{A}\left(\theta^{*}=36^{\circ}, n=150,000 \mathrm{~min}^{-1}\right)$.

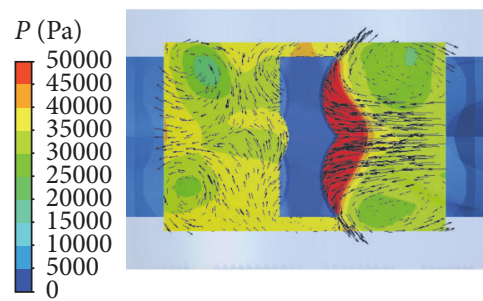

(a) Section a-a

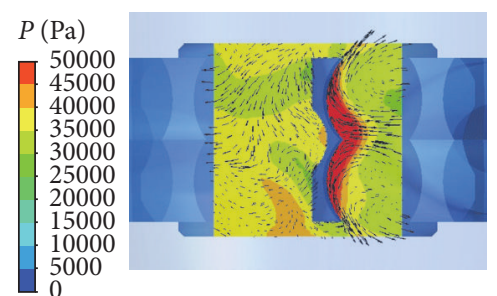

(b) Section b-b

FIGURE 24: Static pressure distributions and absolute velocity vectors of Blade $\mathrm{B}\left(\theta^{*}=36^{\circ}, n=150,000 \mathrm{~min}^{-1}\right)$.

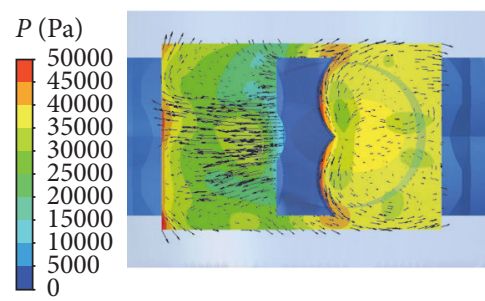

(a) Section a-a

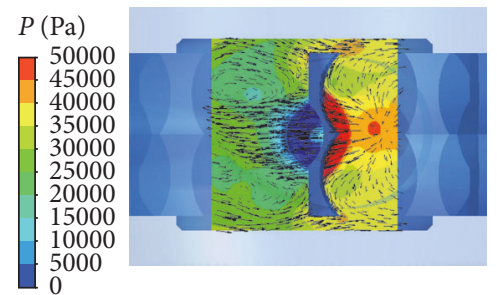

(b) Section b-b

FiguRE 25: Static pressure distributions and absolute velocity vectors of Blade A $\left(\theta^{*}=48^{\circ}, n=150,000 \mathrm{~min}^{-1}\right)$.

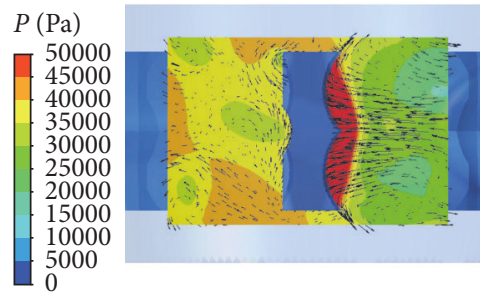

(a) Section a-a

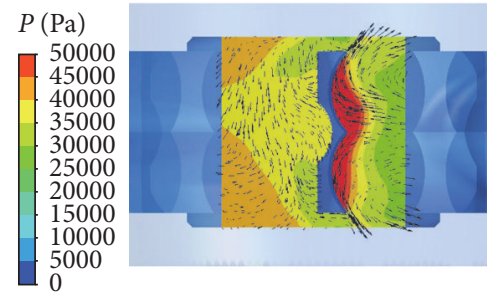

(b) Section b-b

FIGURE 26: Static pressure distributions and absolute velocity vectors of Blade B $\left(\theta^{*}=48^{\circ}, n=150,000 \mathrm{~min}^{-1}\right)$.

relative speed of the jet to the blade decreased. As shown in Figures 27-30, compared to when $n=250,000 \mathrm{~min}^{-1}$, the jet spreads in the width direction of the blade, and the flow that entered the front surface of the blade does not exit along the blade, reducing the shift in the flow. Especially when $\theta^{*}$ $=36^{\circ}$, static pressure at the back surface of Blade A increased more than when $n=250,000 \mathrm{~min}^{-1}$. Therefore, as shown in Figure 14, when $n=400,000 \mathrm{~min}^{-1}$, torque was small and the fluctuation of the torque increased, showing a negative torque at $\theta^{*}=36^{\circ}$. 


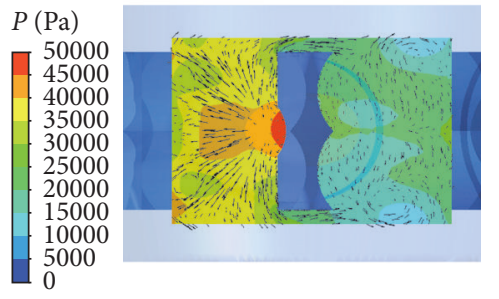

(a) Section a-a

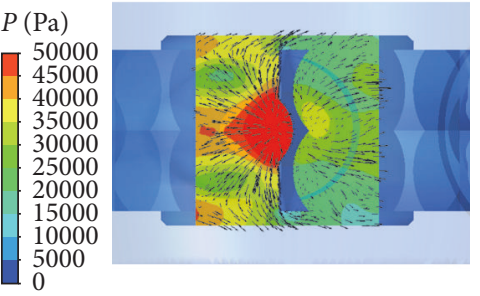

(b) Section b-b

FIGURE 27: Static pressure distributions and absolute velocity vectors of Blade A $\left(\theta^{*}=36^{\circ}, n=400,000 \mathrm{~min}^{-1}\right)$.

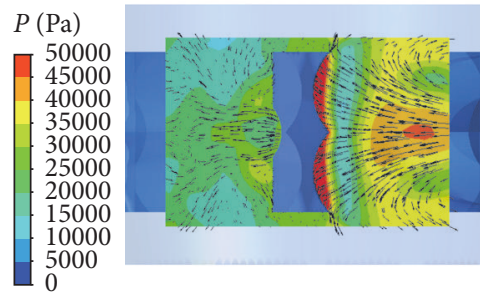

(a) Section a-a

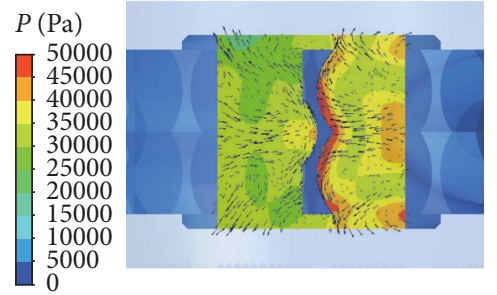

(b) Section b-b

FIGURE 28: Static pressure distributions and absolute velocity vectors of Blade B $\left(\theta^{*}=36^{\circ}, n=400,000 \mathrm{~min}^{-1}\right)$.

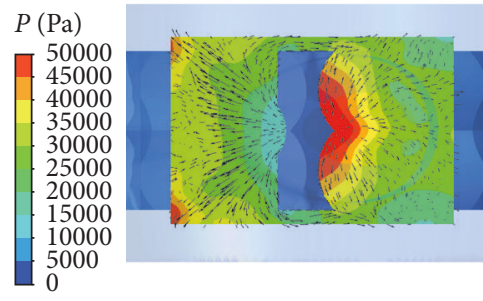

(a) Section a-a

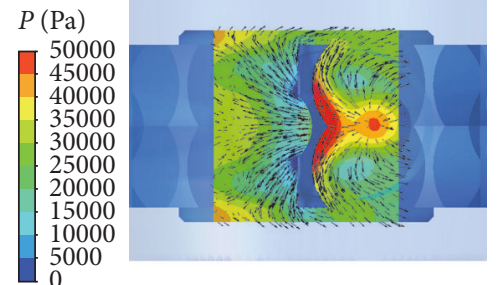

(b) Section b-b

FIGURE 29: Static pressure distributions and absolute velocity vectors of Blade A $\left(\theta^{*}=48^{\circ}, n=400,000 \mathrm{~min}^{-1}\right)$.

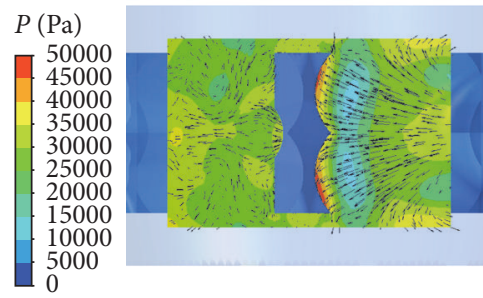

(a) Section a-a

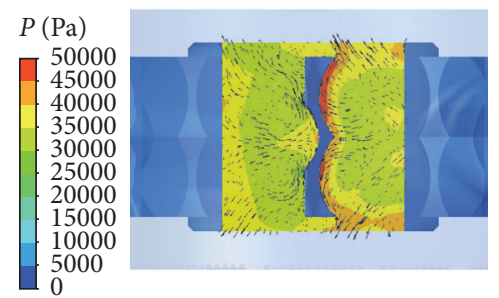

(b) Section b-b

FIGURE 30: Static pressure distributions and absolute velocity vectors of Blade B $\left(\theta^{*}=48^{\circ}, n=400,000 \mathrm{~min}^{-1}\right)$.

\section{Conclusions}

We examined performance and internal flow of a dental air turbine handpiece through experiments and numerical analysis and obtained the following findings:

(1) Experimental and calculated values of torque and turbine output were consistent in the constant speed load method with a descending speed of $1 \mathrm{~mm} / \mathrm{min}$.

(2) Loss in the rotor region is dominant in the loss inside of the handpiece.
(3) The maximum value of adiabatic efficiency in the turbine section was approximately 0.185 , which is quite low. Adiabatic efficiency of the whole handpiece decreased approximately $46 \%$ compared to the efficiency in the turbine section.

(4) With an increase in the rotational speed, the torque decreases but its fluctuation increases.

(5) When the blade tip is located near the center of the nozzle, the torque attains its maximum value. This is because 
the jet enters the tip of the blade at a close enough distance to not reduce its speed and then it flows out along the blade.

\section{Nomenclature}

\author{
b: $\quad$ Blade width, $\mathrm{mm}$ \\ B: $\quad$ Casing width, $\mathrm{mm}$ \\ $d$ : Nozzle inner diameter, $\mathrm{mm}$ \\ $D_{1}$ : Rotor outer diameter, $\mathrm{mm}$ \\ $\mathrm{D}_{2}$ : Rotor inner diameter, $\mathrm{mm}$ \\ $\mathrm{D}_{3}$ : Casing inner diameter, $\mathrm{mm}$ \\ E: Entropy, $\mathrm{J} / \mathrm{kg} \cdot \mathrm{K}$ \\ $F_{H}$ : Horizontal force, $\mathrm{N}$ \\ $L: \quad$ Turbine output, $\mathrm{W}=2 \pi n T / 60$ \\ $L_{\text {ad }}$ : Adiabatic air power, $\mathrm{W}$ \\ $\dot{m}$ : Mass flow rate, $\mathrm{kg} / \mathrm{s}$ \\ n: $\quad$ Rotational speed, $\min ^{-1}$ \\ $P$ : $\quad$ Static pressure, $\mathrm{Pa}$ \\ $r$ : Radius of test bar, $\mathrm{mm}$ \\ $T:$ Torque, $\mathrm{N} \cdot \mathrm{m}=F_{H} r / 1000$ \\ v: Absolute velocity, $\mathrm{m} / \mathrm{s}$.
}

\section{Greek Letters}

$$
\begin{aligned}
& \beta: \quad \text { Blade angle, }{ }^{\circ} \\
& \eta_{\mathrm{ad}}: \text { Adiabatic efficiency }=L / L_{\mathrm{ad}} \\
& \theta^{*}: \text { Blade phase angle, } \\
& \kappa: \quad \text { Specific heat ratio } \\
& \rho: \quad \text { Fluid density, } \mathrm{kg} / \mathrm{m}^{3} .
\end{aligned}
$$

\section{Conflicts of Interest}

The authors declare that there are no conflicts of interest regarding the publication of this paper.

\section{Acknowledgments}

The authors extend their appreciation to Mr. Takuma Komuro of Ibaraki University in helping them run the experiments and numerical analysis.

\section{References}

[1] H. Miyairi, "Dental air turbine hand pieces," Journal of the Society of Mechanical Engineers, vol. 100, no. 949, pp. 1221-1223, 1997 (Japanese).

[2] H. Miyairi, H. Fukuda, and M. Nagai, "Studies on the performance of the dental air turbine handpieces: (part 7) the rotational performance and test method of the dental air turbine handpieces," Journal of the Japanese Society for Dental Materials and Devices, vol. 1, no. 4, pp. 328-337, 1982 (Japanese).

[3] M. Taira, K. Wakasa, M. Yamaki, K. Ohmoto, N. Satou, and H. Shintani, "Fundamental Studies on High-speed Rotational Properties of Dental Air-turbine Handpieces," Journal of the Japanese Society for Dental Materials and Devices, vol. 13, no. 4, pp. 381-387, 1994 (Japanese).

[4] J. E. Dyson and B. W. Darvell, "Dental air turbine handpiece performance testing," Australian Dental Journal, vol. 40, no. 5, pp. 330-338, 1995.
[5] J. E. Dyson and B. W. Darvell, "Flow and free running speed characterization of dental air turbine handpieces," Journal of Dentistry, vol. 27, no. 7, pp. 465-477, 1999.

[6] J. E. Dyson and B. W. Darvell, "Torque, power and efficiency characterization of dental air turbine handpieces," Journal of Dentistry, vol. 27, no. 8, pp. 573-586, 1999.

[7] H. Kimura and M. Kusano, "Basic studies on development of new type air turbine handpiece for dental use. Part 1. Analysis of noise from air turbine handpiece for dental use," Shika zairyo, kikai = Journal of the Japanese Society for Dental Materials and Devices, vol. 7, no. 5, pp. 829-833, 1988.

[8] T. Nomura, M. Itou, M. Uchida, Y. Yajima, and T. Takamata, "Examination of the Stillness Sound Design of an Air Turbine Handpiece for Dentistry : 1 . Noise evaluation of different types of turbine wings," Journal of the Matsumoto Dental University Society, vol. 24, no. 1, pp. 58-71, 1998 (Japanese).

[9] J. Lee and K. Kim, "Numerical Study on the Effect of Turbine Blade Shape on Performance Characteristics of a Dental Air Turbine Handpiece," Korean Society of Machine Tool Engineers, vol. 13, pp. 34-42, 2009 (Korean).

[10] M. Juraeva, K. J. Ryu, and D. J. Song, "Optimum design of a sawtooth-shaped dental air-turbine using design of experiment," International Journal of Precision Engineering and Manufacturing, vol. 15, no. 2, pp. 227-234, 2014.

[11] J. Makhsuda, B. Hwan Park, J. Kyung Ryu, and J. Dong Song, "Computational Approach to Improve the Performance of the Air-Turbine With Different Type Impeller Blades For the Dental Handpiece," International Journal of Mechanical and Production Engineering, vol. 4, no. 10, pp. 95-99, 2016.

[12] K. J. Ryu, M. Juraeva, B. H. Park, and D. J. Song, "Computational Approach to Improve the Performance of the Air-Turbine With Gull Type Impeller Blade For the High-Speed Dental Handpiece," International Journal of Mechanical and Production Engineering, vol. 4, no. 10, pp. 100-104, 2016.

[13] J. Makhsuda, B. H. Park, K. J. Ryu, and D. J. Song, "Optimum Design of the Air-Turbine for the High-Speed Dental AirTurbine Hand piece using Design of Experiment," International Journal of Mechanical and Production Engineering, vol. 5, no. 4, pp. 34-38, 2017.

[14] M. Juraeva, B. H. Park, K. J. Ryu, and D. J. Song, "Computational Approach to Design the High-Speed Dental Air-Turbine Hand piece," International Journal of Management and Applied Science, vol. 5, no. 4, pp. 30-33, 2017.

[15] ANSYS, Inc., "ANSYS CFX-Solver Theoretical guide”, pp. 81-85, 2010.

[16] F. R. Menter, "Two-equation eddy-viscosity turbulence models for engineering applications," AIAA Journal, vol. 32, no. 8, pp. 1598-1605, 1994.

[17] ANSYS, Inc., "ANSYS CFX-Solver Modeling guide”, pp. 144145, 2010. 


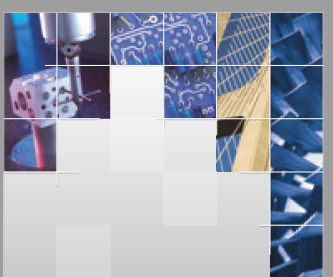

\section{Enfincering}
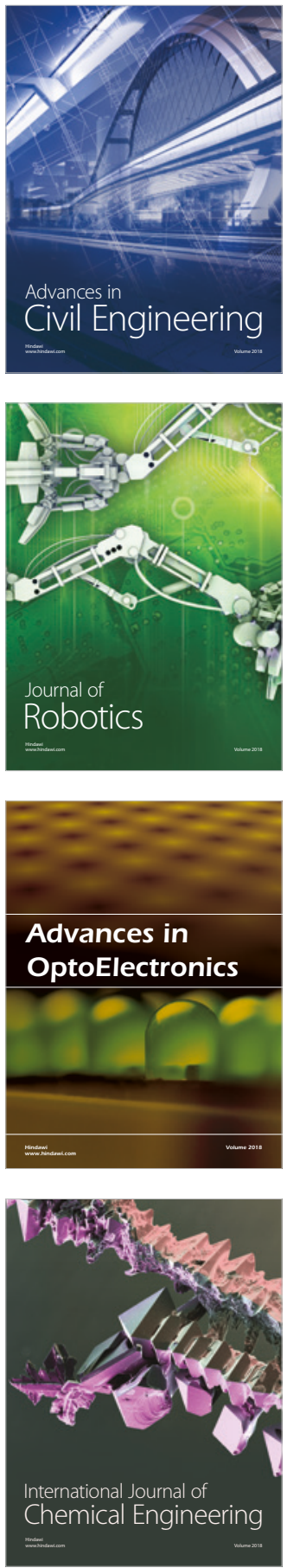

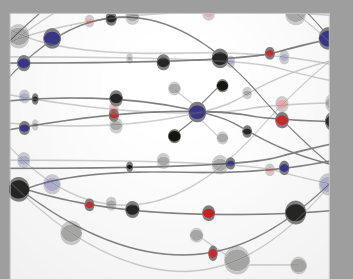

\section{Rotating \\ Machinery}

The Scientific World Journal

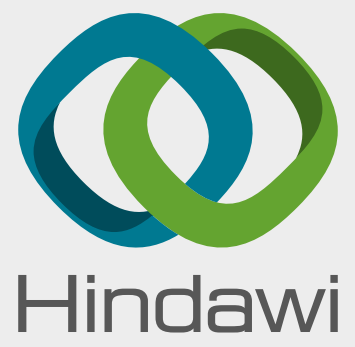

Submit your manuscripts at

www.hindawi.com
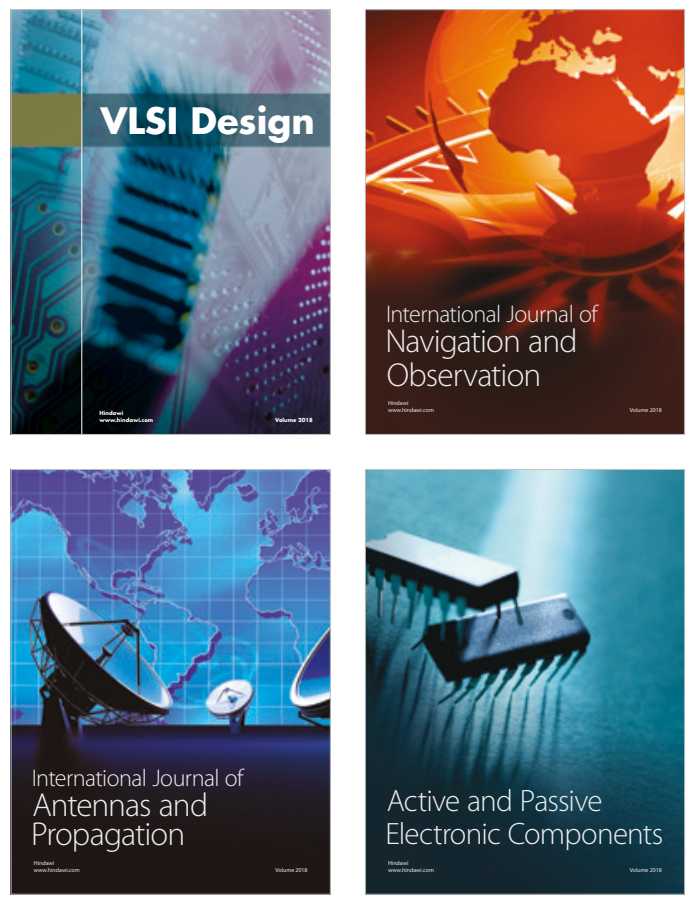
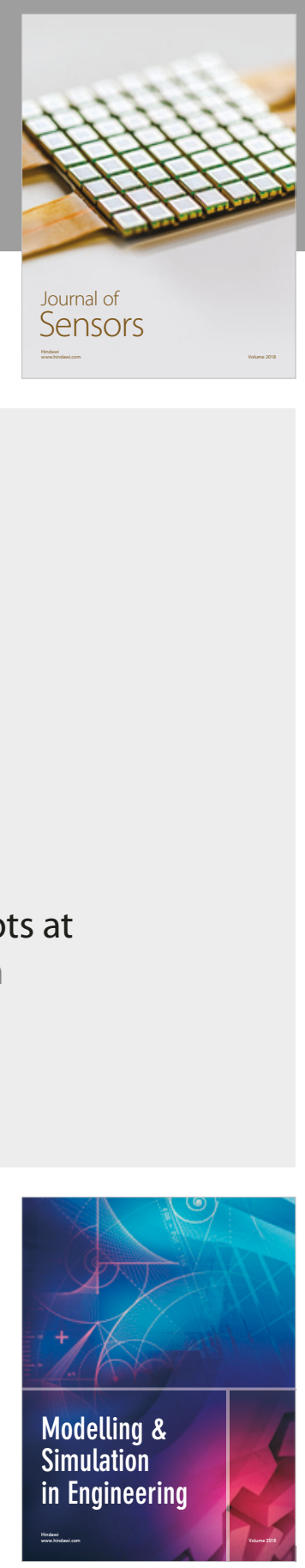

\section{Advances \\ Multimedia}
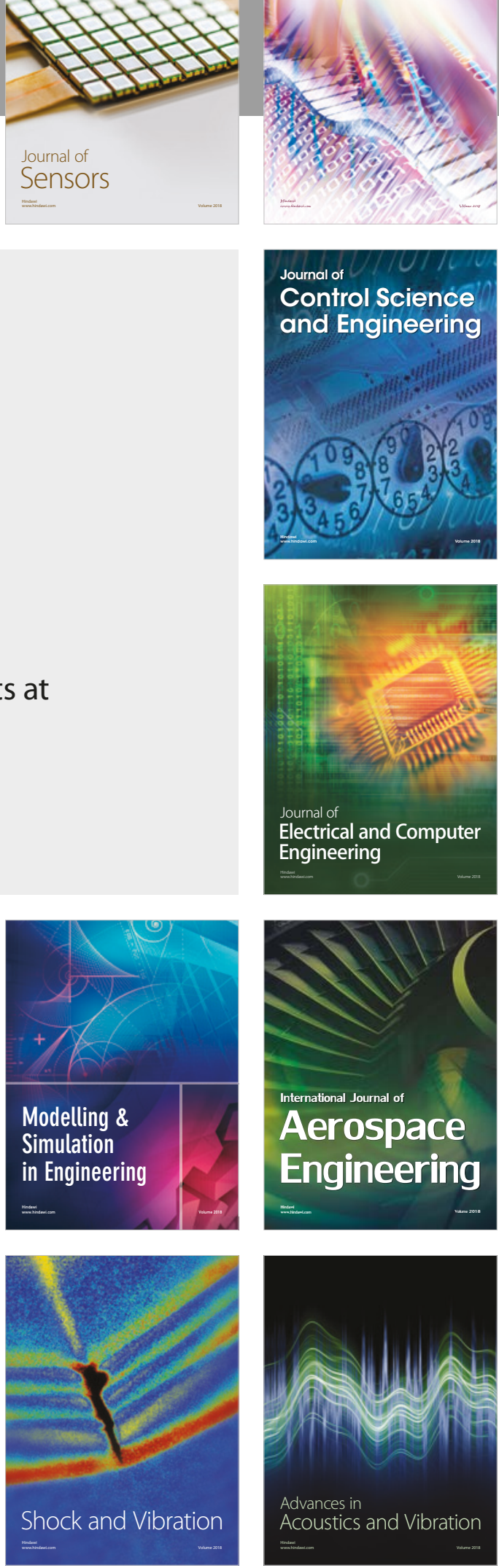